\title{
REMOVAL OF PHENOL AND 2-CHLOROPHENOL BY BANANA BUNCH ACTIVATED CARBON PREPARED BY HYDROTHERMALLY-ASSISTED KOH ACTIVATION
}

\author{
Allwar Allwar \\ Department of Chemistry, Faculty Mathematics and Natural Sciences, \\ Indonesia Islamic University, Yogyakarta, 55584, Indonesia \\ E-mail: allwar@uii.ac.id
}

\begin{abstract}
Activated carbon from banana bunch was successfully prepared using potassium hydroxide activation under low hydrothermal carbonization. The resulted activated carbon were characterized and used as an adsorbent for the removal of phenol and 2-chlorophenol. Pore structures were intensively evaluated involving surface area and pore size distribution. The values of surface area and pore radius were $608 \mathrm{~m}^{2} / \mathrm{g}$ and $2.7 \mathrm{~nm}$, respectively. The Fourier Transform Infrared (FTIR) analysis showed that the carbon might have higher oxygen functional. Morphology structure exhibited a smooth surface with varied pore size dimension. Equilibrium adsorption of phenol and 2-chlorophenol onto activated carbon shows that the Freundlich isotherm is more popular due to having the best correlation coefficient $\left(R^{2}>0.9\right)$. Kinetic adsorption was identified as pseudo-second order with $\mathrm{R}^{2}>0.9$.

Keywords: Banana Bunch, Activated Carbon, KOH, Phenol, 2-Chlorophenol, Hydrothermal
\end{abstract}

() RASĀYAN. All rights reserved

\section{INTRODUCTION}

Water pollution has been a major problem in the environmental system due to the release of toxic chemicals from various industrial wastes. Phenol and 2-chlorophenol are considered as high toxicity even at low concentrations because of their carcinogenicity and heath disorders. Adsorption process using activated carbon is the most favorable method for waste water treatment. Activated carbon is well-known adsorbent due to their excellent pore structures including high surface area, pore size distribution, pore volume and rich of functional groups ${ }^{1,2}$. In recent years, researchers have been focused on how to find a new source of raw material for activated carbon production. Agricultural waste containing high lignocellulose is more promising with many advantages as precursor due to its available in large quantity ${ }^{3}$. Technology treatment might solve the problem of agricultural waste and create waste into a valuable product as an adsorbent.

The requirement of activated carbon steadily increases and has not been replaced yet by the zeolites, polymer and other new-adsorbents ${ }^{4,5}$. It can be seen from the constantly increasing a number of publications of activated carbon. Considerable efforts have been increasingly directed to find new alternative raw materials including a basic understanding of the pore characteristics such as pore structure and the functional group of activated carbon ${ }^{6}$. Explorations of raw material such as banana bunch have encouraged the researcher interests to study the specific activated carbon which is suitable with a certain application. The major challenge in the activated carbon is its adsorption capacity which is mostly influenced by the preparation condition and type of raw materials.

The objective of this study is to obtain activated carbon from a solid banana bunch using chemical activation of $\mathrm{KOH}$. Characterization of the porous structure is investigated by the Scanning Electron Microscopy and Energy Dispersive Spectrometer (SEM-EDS), Fourier Transform Infrared Spectrometer (FTIR) and Surface Area Analyzer (SAA) methods. The effectiveness of carbon was examined for removal of phenol and 2-chlorophenol. The adsorption process was carried out with different experiments such as $\mathrm{pH}$ solution, concentration, contact time and adsorbent dosage. Determination of phenol and 2-chlorophenol removal

Rasayan J. Chem., 12(2), 598-607(2019)

http://dx.doi.org/10.31788/RJC.2019.1225090

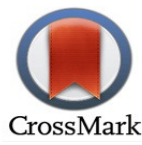


onto activated carbon was conducted by the Ultraviolet-Visible (UV-Vis) spectrophotometry. The Langmuir and Freundlich isotherm models were carried out to obtain the equilibrium isotherm adsorption.

\section{Material and Methods}

\section{EXPERIMENTAL}

Banana bunch as a solid waste was collected from a banana farmer around Yogyakarta, Indonesia and used as a precursor for activated carbon production. Sample was dried for $24 \mathrm{~h}$ and grounded to powder sizes. Chemicals such as potassium hydroxide $(\mathrm{KOH})$, nitric acid $\left(\mathrm{HNO}_{3}\right)$, hydrochloric acid $(\mathrm{HCl})$, phenol and 2-chlorophenol were supplied from Merck.

\section{Preparation of Activated Carbon}

The banana bunches were cut down into small pieces in the range of 1-2 mm and washed with distilled water in order to remove the impurities on the surface. Then, the banana bunches were dried overnight at $110^{\circ} \mathrm{C}$. The samples were impregnated with $30 \% \mathrm{KOH}$ solution and refluxed at $85^{\circ} \mathrm{C}$ for $5 \mathrm{~h}$. Afterward, the mixtures were filtered, washed and dropped with $\mathrm{HCl}$ solution to reduce basic contain in the range of $\mathrm{pH}$ 6-7. After impregnation, samples were dried overnight at $110^{\circ} \mathrm{C}$. Carbonization process was carried out into the hydrothermal reactor under wet condition using distilled water. The hydrothermal reactor was placed into graphite furnace and heated up at $250^{\circ} \mathrm{C}$ for $5 \mathrm{~h}$. After cooling down, resulted activated carbons were modified with $2 \mathrm{M} \mathrm{HNO3}$ in order to remove impurities that occurred during carbonization. Finally, the activated carbon was dried at $120^{\circ} \mathrm{C}$ for $24 \mathrm{~h}$. and kept in a desiccator for further analysis.

\section{Characterizations of Activated Carbon}

Banana bunch activated carbon was intensively studied its characterization. Surface area analyzer was used for determination of the pore structures such as surface area, total pore volume and pore size distribution based on the nitrogen adsorption-desorption isotherm data at $77 \mathrm{~K}$. The relative pressures were measured based on the range of 0.01-0.99. FTIR analysis having wave number within a range of $400-4000 \mathrm{~cm}^{-1}$ was performed to determine the functional groups. The SEM-EDS was conducted to study the surface morphology and elemental analysis of activated carbon.

\section{Removal of Phenol and 2-Chlorophenol}

Determination of adsorption capacity of activated carbon was investigated from the removal of phenol and 2-chlorophenol. Experiments were conducted in a batch mode and at the different adsorption parameters involving $\mathrm{pH}$ solution, concentration, and weight dosage and contact times. The sorption rates of phenol and 2-chlorophenol adsorbed onto activated carbon were calculated by the UV-Vis Spectrophotometry. The adsorption isotherms were calculated by the Langmuir and Freundlich models.

\section{RESULTS AND DISCUSSION \\ Nitrogen Adsorption-Desorption Isotherm of Activated Carbon}

The extent of pore structures were calculated from the isotherm data at $77 \mathrm{~K}$. The curve of isotherm is shown Fig.-1. The curve slightly increased from low pressure and sharply increased at higher relative pressure which corresponds to the multilayer. The presence of hysteresis could be related to the mostly mesoporous structure ${ }^{7}$.The isotherm type closed to Type IV corresponding to mesoporous structures. However, desorption isotherm shows the uncommon shape in which it should return to the adsorption isotherm at low relative pressure $(\mathrm{P} / \mathrm{Po}<0.4)$. It was assumed that the porosity was created from the soft materials that can be easily broken and shrinkage during the desorption process. The Brunauer-Emmett-Teller (BET) and Barret-Joyner-Halenda analysis were conducted to obtain the values of surface area and pore volume. Textural characteristics of activated carbon were displayed in Table-1.

\section{Morphology Structure of Activated Carbon}

The morphology images of activated carbon prepared from the banana bunch with different magnifications are shown in Fig.-2. The image at 1000 magnification shows that the pores are covered with the fraction of particles of activated carbon and the rest of the chemicals. However, at 10.000 magnifications, the surface 
RASĀYAN J. Chem.

Vol. 12 | No. 2 |598-607 | April - June | 2019

of activated carbon shows high disorder cavities with the unsmooth formation. The images of porosity look very clear assumed due to the optimum carbonization process ${ }^{8}$. Elemental analysis of activated carbon was obtained from the EDS analysis which is displayed in Fig.-3. Carbon (38.05\%) and oxygen (26.88\%) contents could be from the cellulosic material as a source of raw material. The presence of potassium $(11.34 \%)$ is assumed as a result of the reaction between cellulose of raw material and $\mathrm{KOH}$ as chemical activation which was considered as the main reaction to form activated carbon. The rest elements such as $\mathrm{Al}, \mathrm{Si}, \mathrm{Mg}$, and $\mathrm{Ca}$ ions could not be removed at low hydrothermal carbonization which might be from the internal of raw materials.

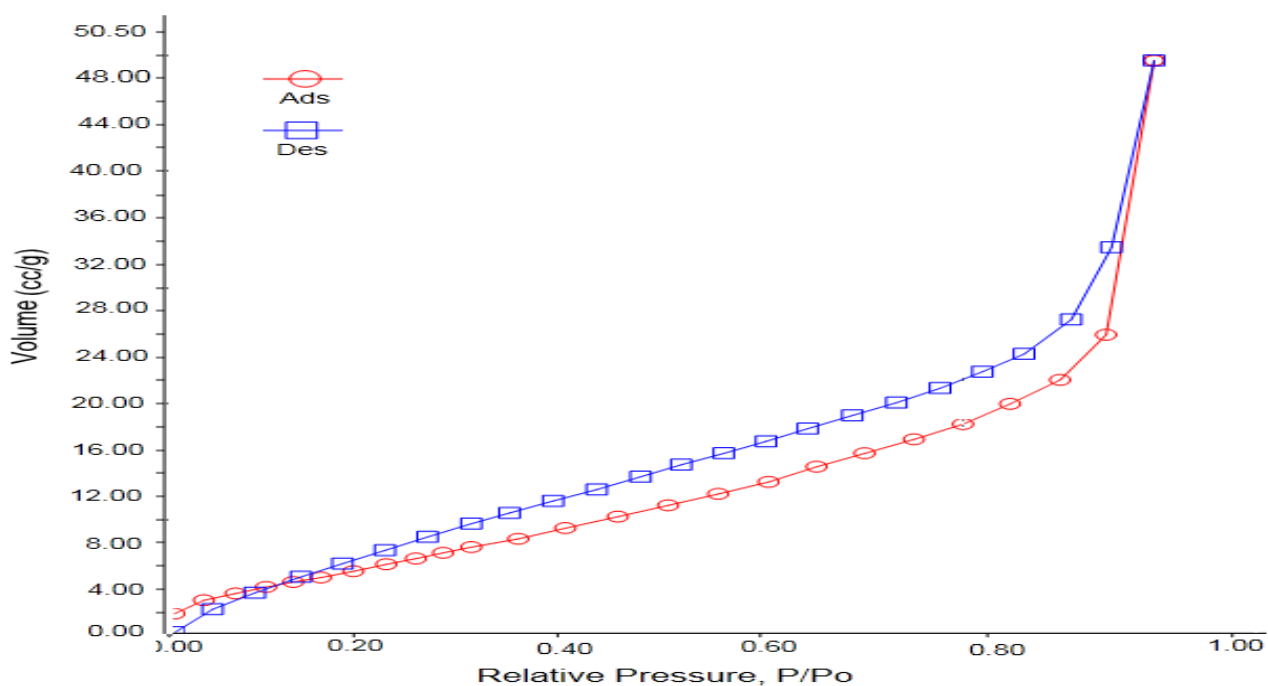

Fig.-1. Nitrogen Desorption Adsorption Isotherm at 77K for Activated Carbon

Table-1. Pore structure from $\mathrm{N}_{2}$ Adsorption-desorption Isothermal Data

\begin{tabular}{c|c|c|c}
\hline $\begin{array}{c}\text { BET Surface } \\
\text { Area }\end{array}$ & BJH Pore Radius & $\begin{array}{c}\text { Total Pore Volume at } \\
\text { P/Po 0.99 }\end{array}$ & $\begin{array}{c}\text { t-Plot Method External } \\
\text { Surface Area }\end{array}$ \\
\hline $608 \mathrm{~m}^{2} / \mathrm{g}$ & $2.7 \mathrm{~nm}$ & $0.08 \mathrm{~cm}^{3} / \mathrm{g}$ & $348 \mathrm{~m}^{2} / \mathrm{g}$ \\
\hline
\end{tabular}
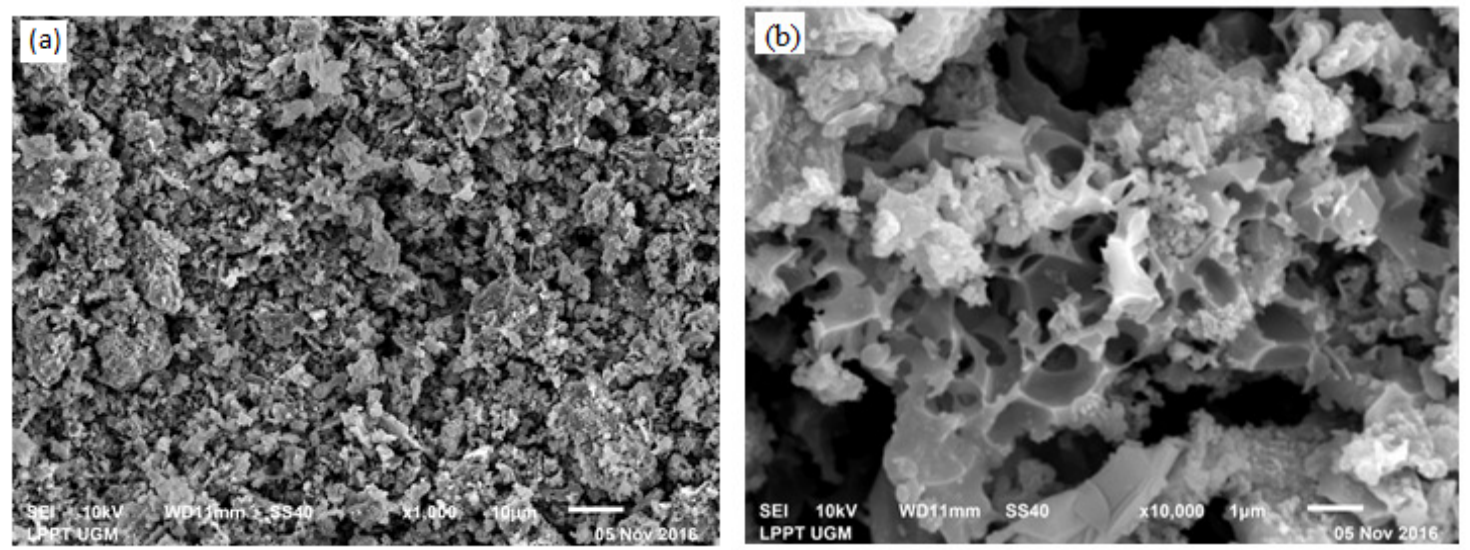

Fig.-2: SEM Image of Banana Bunch Activated Carbon (a) 1000, (b) 10.000 Magnification

\section{Functional Groups of Activated Carbon}

The FTIR spectra of the activated carbon are shown in Fig.-4. The thestrong peak at $3336 \mathrm{~cm}^{-1}$ is associated with O-H stretching vibration of hydroxyl which was from $\mathrm{KOH}$. The weak peak at $1576 \mathrm{~cm}^{-1}$ is assigned to the $\mathrm{C}=\mathrm{C}$ stretching vibration of aromatic rings. The peak at $1376 \mathrm{~cm}^{-1}$ corresponds to $\mathrm{C}=\mathrm{O}$ and $\mathrm{C}-\mathrm{O}$ of the carboxylic group which is indicative of oxygen-containing functional groups. The strong peak at 1007 
$\mathrm{cm}^{-1}$ is attributed to the $\mathrm{C}-\mathrm{O}$ and $\mathrm{C}-\mathrm{OH}$ group in alcohol, phenol or ester. The presences of C-H in out-ofplane at the edges of aromatic rings or $\mathrm{C}$ - halogen on the surface were observed in the peak of $871 \mathrm{~cm}^{-1}$. The peak at $447 \mathrm{~cm}^{-1}$ might be assumed as the bonding of metal oxides such as $\mathrm{K}-\mathrm{O}, \mathrm{Al}-\mathrm{O}$ or $\mathrm{Mg}-\mathrm{O}^{9}$. The result of the FTIR spectra indicated that the activated carbon shows high oxygen functional groups. The formation of the functional group could be supported by the low hydrothermal carbonization process.

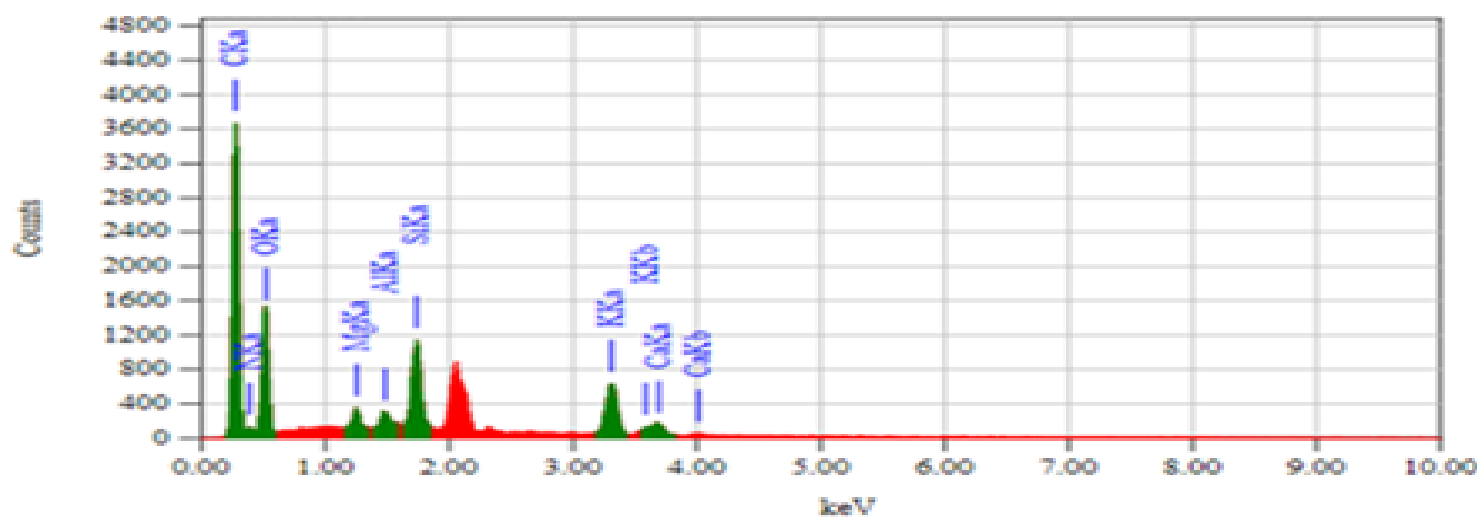

\begin{tabular}{|l|c|c|c|c|c|}
\hline \multicolumn{7}{|l|}{ Fitting coefficient : 0.1613} & & & \\
\hline Element & (keV) & Mass, \% & Sigma & Atom, \% & K \\
\hline C & 0.277 & 38.05 & 0.13 & 49.37 & 337.638 \\
\hline $\mathrm{N}$ & 0.392 & 12.72 & 0.27 & 14.15 & 103.036 \\
\hline $\mathrm{O}$ & 0.525 & 26.88 & 0.25 & 26.18 & 224.722 \\
\hline $\mathrm{Mg}$ & 1.253 & 1.19 & 0.04 & 0.77 & 15.467 \\
\hline $\mathrm{Al}$ & 1.486 & 0.89 & 0.04 & 0.51 & 12.139 \\
\hline $\mathrm{Si}$ & 1.739 & 6.18 & 0.09 & 3.43 & 11.119 \\
\hline $\mathrm{K}$ & 3.312 & 11.34 & 0.18 & 4.52 & 172.956 \\
\hline Ca & 3.69 & 2.75 & 0.11 & 1.07 & 42.922 \\
\hline Total & & 100.00 & & 100.00 & \\
\hline
\end{tabular}

Fig.-3: Elemental Analysis of Banana Bunch Activated Carbon by EDS Method

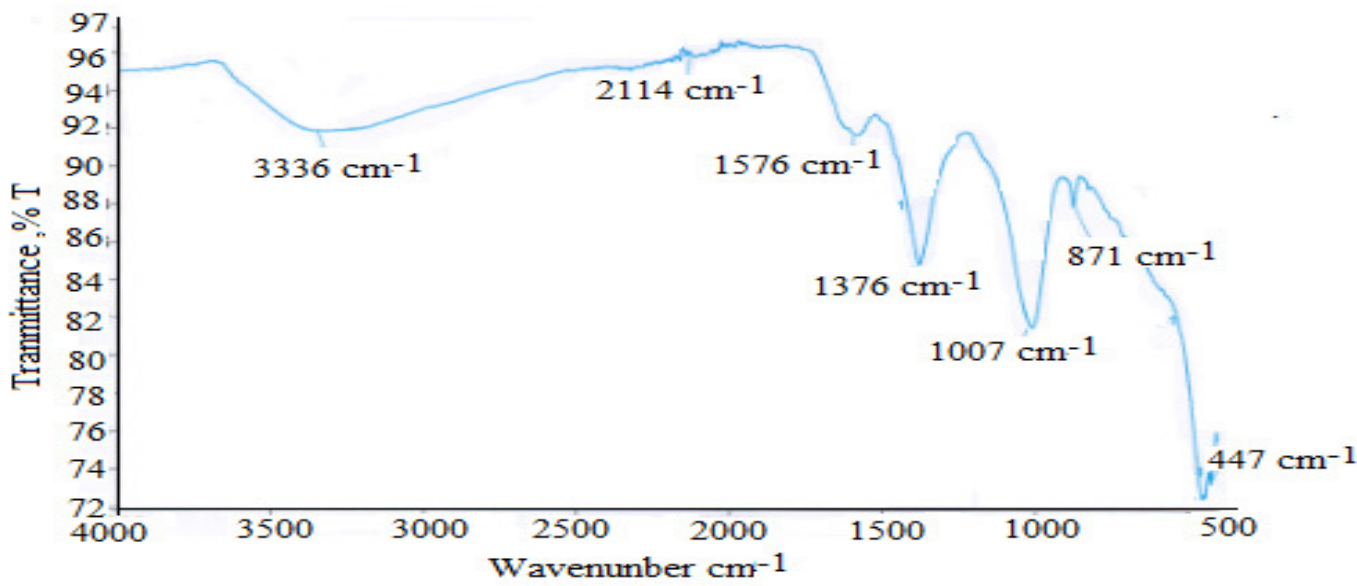

Fig.-4: The FTIR Spectra of Activated Carbon from a Banana Bunch

\section{Adsorption of Phenol and 2-Chlorophenol}

It has been known that phenol and 2-chlorophenol are toxic compounds. Resulted in activated carbon from the banana bunch was considered as an adsorbent for removal of phenol and 2-chlorophenol. Parameter adsorptions were carried out with different experiments such as $\mathrm{pH}$ solution, contact time, concentration and adsorbent dose. 


\section{Effect of pH Solution}

The effect of $\mathrm{pH}$ solution can influence the rate of the adsorption process. In general, activated carbon has amphoteric properties that can be acid or base which depends on the solution of reaction. Comparison studies of phenol and 2-chlorophenol were shown in Fig.-5. Both curves showed nearly plateau from $\mathrm{pH} 2$ to 5 and sharply dropped with the increase of $\mathrm{pH}$ higher than 5 . The optimum efficiency adsorption occurred at low $\mathrm{pH}$ values. The reason is that the surface of activated carbon could produce positively charged with $\mathrm{H}^{+}$ion which may compete with the phenolic compound as the unionized acidic condition. The performance for adsorbing phenolic compounds increased due to the electrostatic attraction between the phenolic compound and the active site of activated carbon. Phenol is a sufficiently acidic compound with pKa 9.5. Therefore, efficiency adsorption decreases at higher $\mathrm{pH}$ solution. The results were assumed that during the adsorption process, the surface of activated carbon attributed negative charges, and the phenolic compound as weak acid was partially ionized charges. In this phenomenon, the negative charge of phenol might be repelled by the negative charge of surface activated carbon as a result of decreasing efficiency removal ${ }^{10,11}$. Overall, the effect of $\mathrm{pH}$ has clearly influenced the efficiency of removal phenol and 2-chlorophenol showing a decrease by the increase $\mathrm{pH}$ solution ${ }^{12}$.

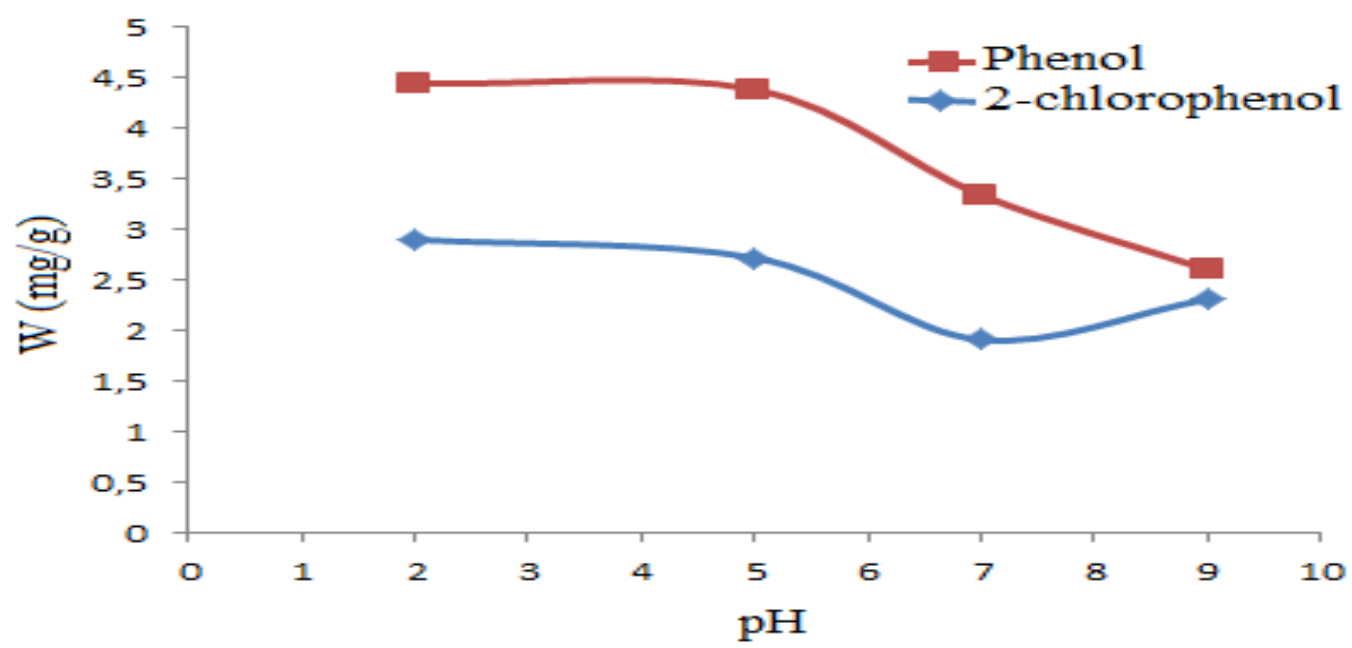

Fig.-5: The Adsorption Capacity of Activated Carbon with Different $\mathrm{pH}$

\section{Effect of Contact Time}

Contact time is an important factor to investigate the mechanism of the adsorption process. The effect of contact time on phenol and 2-chlorophenol removal is shown in Fig.-6. The percentage adsorption increases from initial stages to15 min, slightly decrease for 2-chlorophenol and plate for phenol to the end of the adsorption process. This result can be concluded that at a low contact time, the carbons have an extension of time for the reaction between adsorbates and active sites on the activated carbon. It may also enhance the diffusion or transportation of adsorbates through vacant active sites. However, after 15min, the adsorption process tends to slightly decrease or plate. I was due to the completed reaction in the adsorption process.

\section{Effect of Concentration}

The percentage of adsorption was influenced by phenol and 2-chlrophenol concentration as shown in Fig.7. The adsorption capacity of phenol steadily increased to higher amount of concentration. The adsorption capacity increased with increasing phenol concentration and elevated after $100 \mathrm{mg} / \mathrm{l}$. This result can be explained that increasing phenol concentration produced high interactions occurring between adsorbates and active sites. The mass transfer driving force passed through the solution and a liquid layer of adsorbent. As a result, the efficiency of adsorption reached maximum condition at a concentration of $200 \mathrm{mg} / \mathrm{L}$. In contrast, the adsorption capacity of 2-chlorophenol decreased with the increase of concentration. This could be the limited number of active sites on adsorbent that become saturation at high 2-chlorophenol 
RASĀYAN J. Chem.

Vol. 12 | No. 2 |598-607 | April - June | 2019

concentration $^{13}$. This phenomenon proved that the active site of activated carbon has beensaturationby the adsorbatesstarting from the initial concentration.

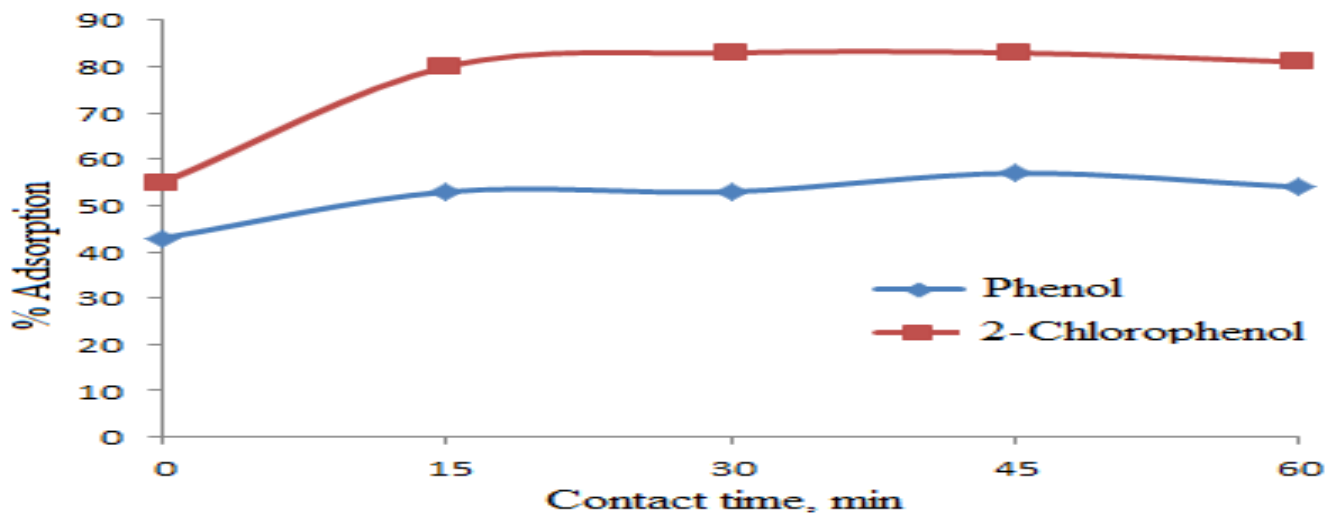

Fig.-6: The Adsorption Capacity of Activated Carbon with Different Contact Times

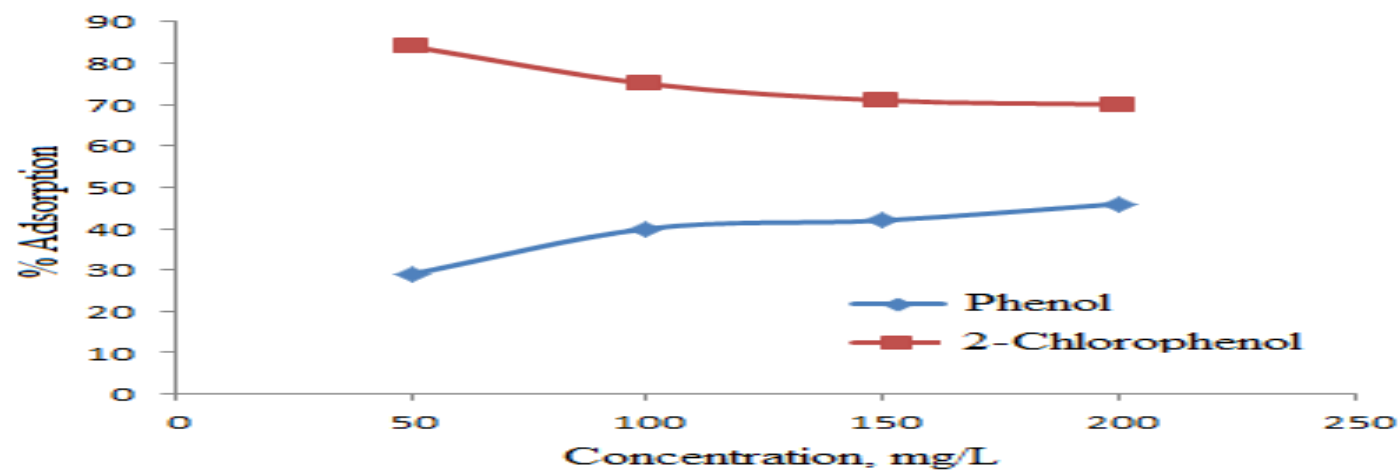

Fig.-7: The Adsorption Capacity of Activated Carbon with Different Concentration

\section{Effect of Adsorbent Dosage}

The effects of adsorbent dosage on the percentage of adsorption are shown in Fig.-8. The efficiency adsorption sharply increased from initial adsorbent dosage, decreased at $1 \mathrm{~g}$ and reached maximum adsorption at $1.5 \mathrm{~g}$. Overall, sorption rates of phenol and 2-chlorophenol were clearly influenced by adsorbent dosage. The reason for this phenomenon is due to the increasing of the active site and interaction occurring between adsorbates and activated carbon ${ }^{14}$.

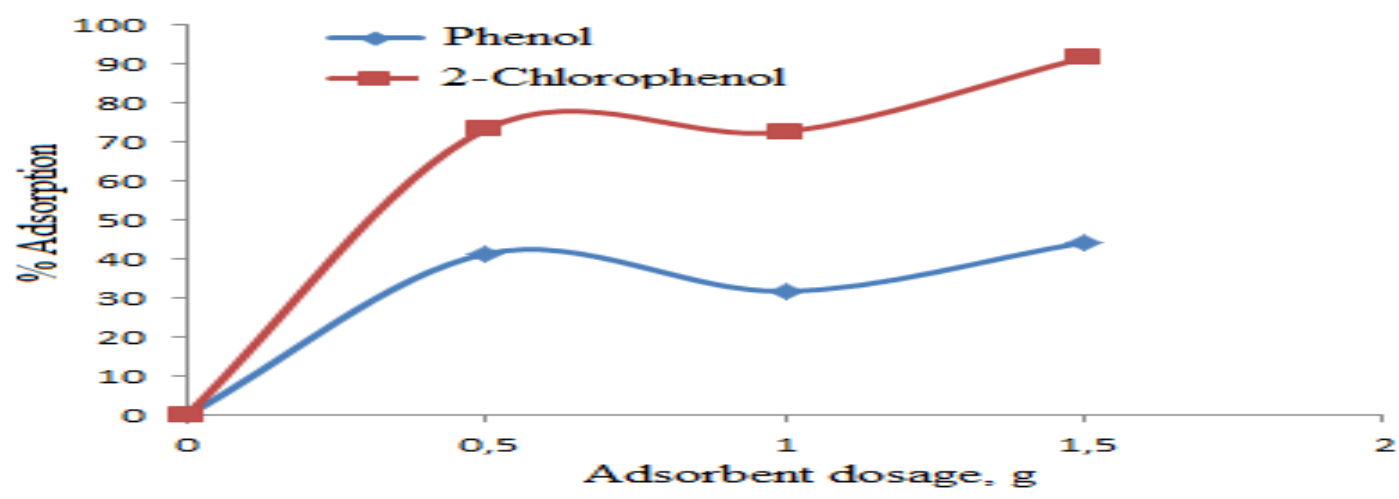

Fig.-8: The Adsorption Capacity of Activated Carbon with Different Adsorbent Dosage

\section{Equilibrium Adsorption}

The equilibrium adsorptionswereinvestigated by the Langmuir and Freundlich isotherms. Langmuir isotherm indicates the presence of monolayer or microporous structures with homogeneous pores on the activated carbon. The Langmuir method is determined by the following eq. 1: 


$$
\frac{\mathrm{C}_{\mathrm{e}}}{\mathrm{q}_{\mathrm{e}}}=\frac{1}{\mathrm{q}_{\mathrm{m}} \mathrm{K}_{\mathrm{L}}}+\frac{\mathrm{C}_{\mathrm{e}}}{\mathrm{q}_{\mathrm{m}}}
$$

where and qe are concentration $(\mathrm{mg} / \mathrm{L})$ and adsorption capacity $(\mathrm{mg} / \mathrm{g})$ at equilibrium state, respectively, $\mathrm{q}_{\mathrm{m}}$ is the maximum adsorption capacity $\left(\mathrm{mg} / \mathrm{g}\right.$ )relating to the monolayer $\mathrm{c}, \mathrm{K}_{\mathrm{L}}$ is the Langmuir constant (L/mg).

The Freundlich isotherm related to the interaction on the mesoporous or multilayer structures as the following eq. 2 :

$$
\log \mathrm{q}_{\mathrm{e}}=\log \mathrm{K}_{\mathrm{F}}+\frac{1}{\mathrm{n}} \operatorname{loq} \mathrm{Ce}
$$

Where $\mathrm{K}_{\mathrm{F}}$ is Freundlich constant with several environmental factors, $\mathrm{n}$ is the energy heterogeneity of the adsorption sites ${ }^{15}$. The equilibrium adsorption of the Langmuir and Freundlich isotherm is shown in Figs.9-11. The Freundlich isotherms of phenol and 2-chlorophenol exhibited the best fit line with the correlation coefficient of $\mathrm{R}^{2}>0.9$. In contrast, the Langmuir isotherms show unfamiliar correlation coefficient with the presence $\operatorname{ofR}^{2}<0.9$. This phenomenon can be concluded that the adsorption process follows multilayer adsorption relating with the heterogeneous mesopores. Table- 2 shows the equilibrium adsorption data of activated carbon from the banana bunch.

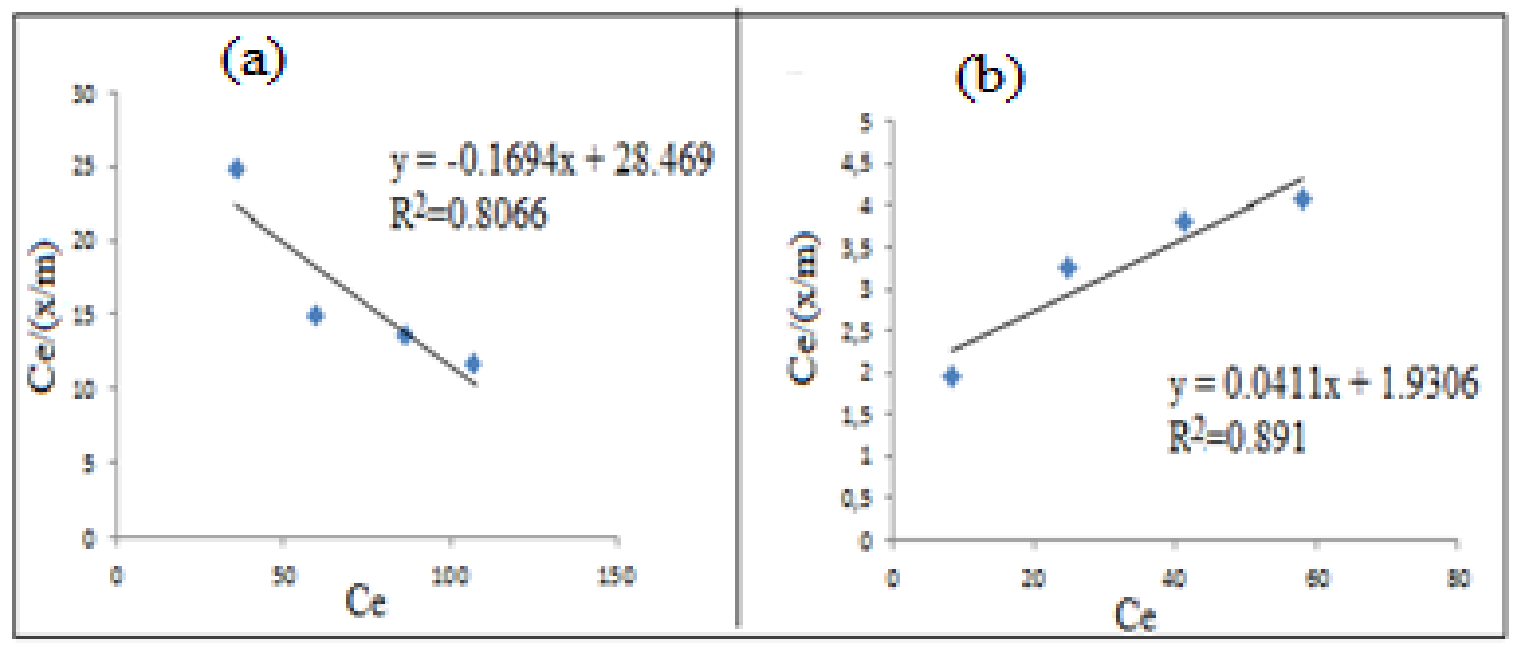

Fig.-9: Equilibrium Adsorption Isotherm Langmuir (a) Phenol (b) 2-Chlorophenol

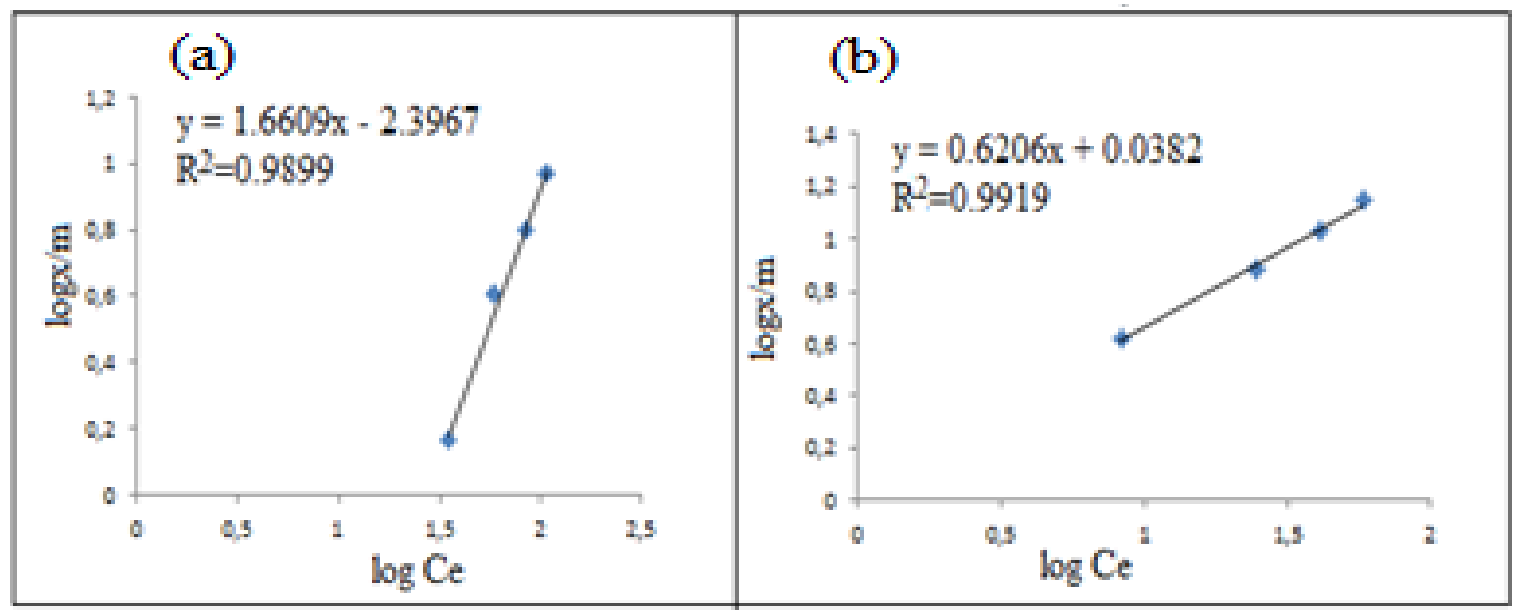

Fig.-10: Equilibrium Adsorption Isotherm Freundlich (a) Phenol, (b) 2-Cholorophenol 


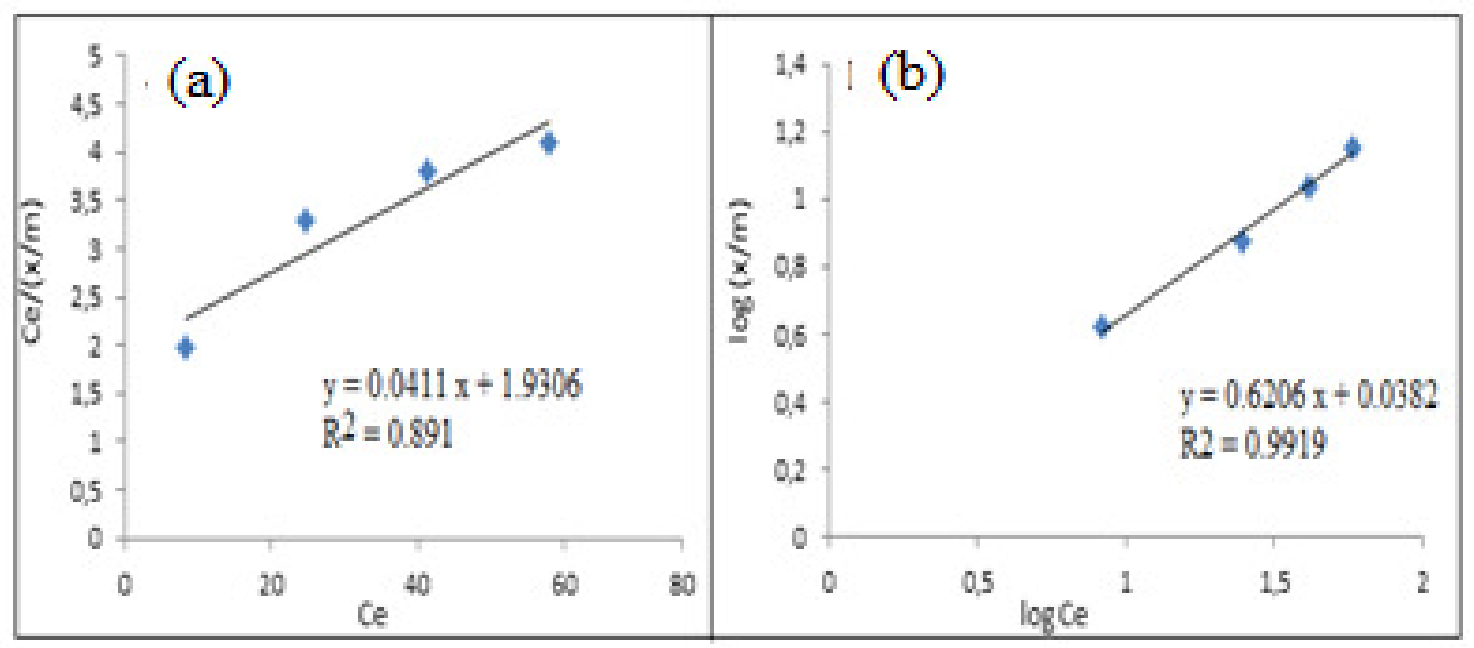

Fig.-11: Equilibrium Adsorption Isotherms of 2-Chlorophenol (a) Langmuir (b) Freundlich

Table-2. Langmuir and Freundlich Isotherms for Phenol and 2-Chlorophenol

\begin{tabular}{c|c|c|c|c|c|c}
\hline \multirow{2}{*}{ Adsorbate } & \multicolumn{3}{|c|}{ Langmuir Isotherm } & \multicolumn{3}{c}{ Freundlich Isotherm } \\
\cline { 2 - 7 } & $\begin{array}{c}\mathrm{q}_{\mathrm{m}} \\
(\mathrm{mg} / \mathrm{g})\end{array}$ & $\begin{array}{c}\mathrm{K}_{\mathrm{L}} \\
(\mathrm{L} / \mathrm{mg})\end{array}$ & $\mathrm{R}^{2}$ & $\mathrm{~K}_{\mathrm{F}}$ & $\mathrm{N}$ & $\mathrm{R}^{2}$ \\
\hline phenol & -5.90319 & -0.00595 & 0.8066 & 0.00636 & 0.60208 & 0.9899 \\
\hline 2-chlorophenol & 24.3309 & 0.021289 & 0.8910 & 1.091943 & 1.611344 & 0.9919 \\
\hline
\end{tabular}

\section{Kinetic Adsorption}

Adsorption kinetic has been widely used to determine the adsorption reaction mechanism and sorption rate. Kinetic adsorptions were investigated based on the pseudo-first-order and pseudo-second-order. A kinetic model for pseudo-first-order was introduced as the following eq. $-3^{16,17}$ :

$$
\log (q e-q t)=\log q e-\frac{K 1}{2,303} t
$$

Where $\mathrm{K}_{1}(1 / \mathrm{min})$ is rate constant of the pseudo-first-order, qt is the amount of adsorption capacity at time $\mathrm{t}$ $(\mathrm{mg} / \mathrm{g})$, qe $(\mathrm{mg} / \mathrm{g})$ is the adsorption capacity at equilibrium and $\mathrm{t}$ is the contact time $(\mathrm{min})$. The correlation coefficient is obtained from the linear curve of $\log (q \mathrm{e}-\mathrm{qt})$ versus $\mathrm{t}$.

In the kinetic model for pseudo-second-order, the equation is given as following eq 4 :

$$
\frac{\mathrm{dq}}{\mathrm{dt}}=\mathrm{K}_{2}\left(\mathrm{q}_{\mathrm{e}}-\mathrm{q}_{\mathrm{t}}\right)^{2}
$$

The $\mathrm{K}_{2}$ (g/mg.min) is the rate constant of pseudo-second-order. The integration in linear form as the following eq. 5 :

$$
\frac{1}{\mathrm{qt}}=\frac{1}{\mathrm{~K}_{2} \mathrm{qe}^{2}}+\frac{1}{\mathrm{qe}} \mathrm{t}
$$

A comparison study of adsorption on kinetic data was further analyzed using the pseudo-first-order and pseudo-second-order. The first-pseudo order of activated carbon is shown on Fig.-12. The result showed that pseudo-first orders of phenol and 2-chlorophenol have poor correlation coefficients $\left(\mathrm{R}^{2}<0.9\right)$ relating to insufficient energy. In contrast, Fig.-13 shows the kinetic adsorption for pseudo-second-order giving the correlation coefficient $\left(\mathrm{R}^{2}=0.9\right)$. The result indicates that the kinetics of phenol and 2-chlorophenol removal were more favorable by the pseudo-second-order model. ${ }^{18,19}$ Table-3 shows the kinetic models for adsorption phenol and 2-chlorophenol on banana bunch activated carbon using pseudo-first-order and pseudo-second-order. 
RASĀYAN J. Chem.

Vol. 12 | No. 2 |598-607 | April - June | 2019

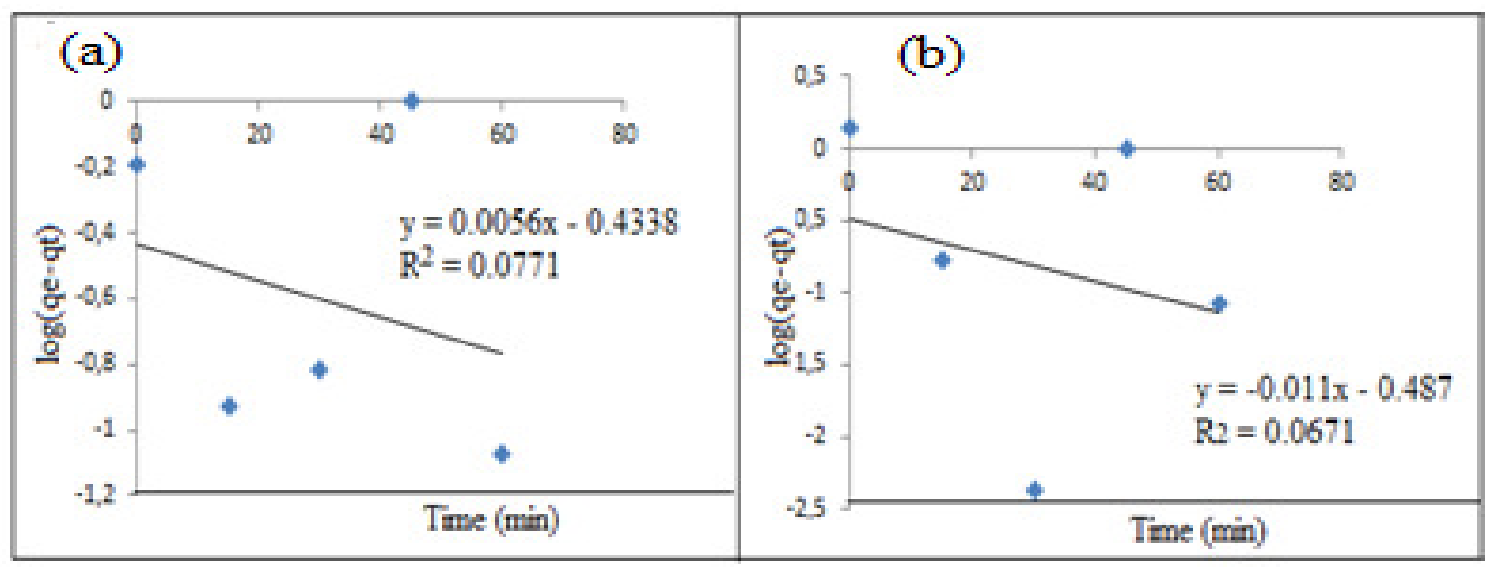

Fig.-12: The Pseudo-First Order (a) Phenol and (b) 2-Chlorophenol

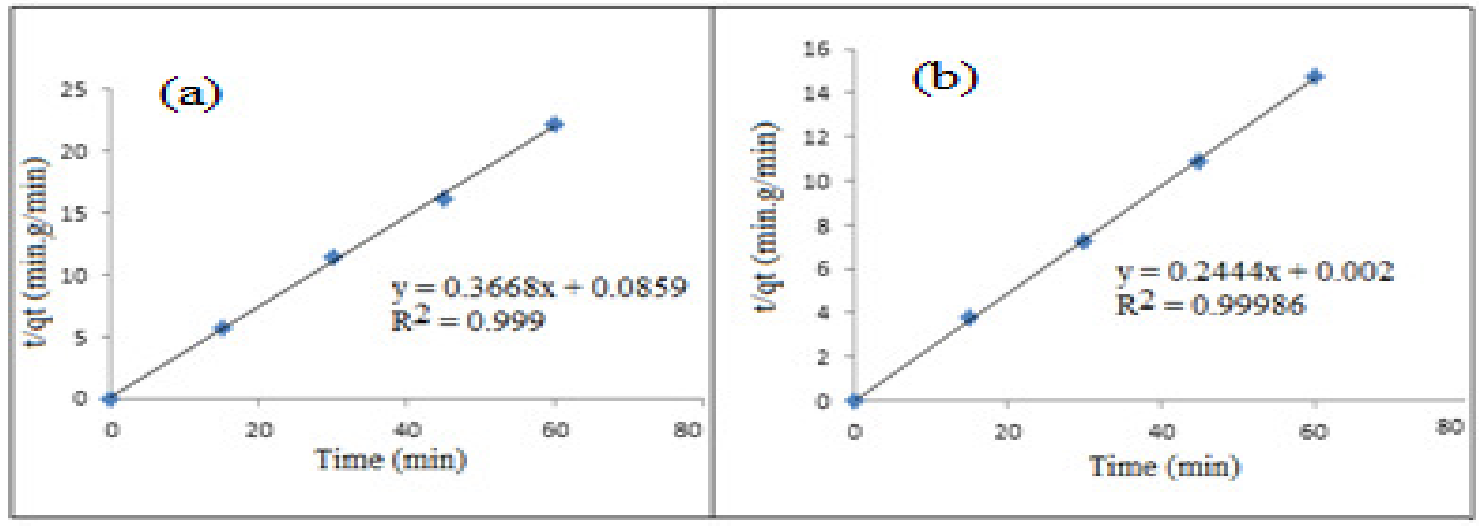

Fig.-13: The Pseudo-Second Order (a) Phenol and (b) 2-Chlorophenol

Table-3: The Pseudo-First and Pseudo-Second Order for Activated Carbon from Banana Bunch

\begin{tabular}{l|l|l|l|l|l|l}
\hline \multirow{2}{*}{ Adsorbates } & \multicolumn{3}{c|}{ Pseudo-First Order } & \multicolumn{3}{c}{ Pseudo-Second Order } \\
\cline { 2 - 7 } & qe $(\mathrm{mg} / \mathrm{g})$ & $\mathrm{K}_{1}(1 / \mathrm{min})$ & $\mathrm{R}^{2}$ & $\begin{array}{c}\text { qe } \\
(\mathrm{mg} / \mathrm{g})\end{array}$ & $\mathrm{K}_{2}(\mathrm{~g} / \mathrm{mg} \cdot \mathrm{min})$ & $\mathrm{R}^{2}$ \\
\hline Phenol & 0.3683 & 0.1289 & 0.0771 & 2.7263 & 1.5663 & 0.999 \\
\hline 2-Chlorophenol & 0.3258 & -0.0253 & 0.0671 & 4.0917 & 29.656 & 0.999 \\
\hline
\end{tabular}

CONCLUSION

In this study, the banana bunch was successfully converted to activated carbon and used as an adsorbent for the removal of phenol and 2-chlorophenol. Physical and chemical characterizations were carried out in detail and showed excellent property for adsorbent. The Freundlich isotherm was demonstrated to the most popular equilibrium adsorption with the best correlation coefficient $\left(\mathrm{R}^{2}>0,9\right)$ for the removal of phenol and 2 -chlorophenol. The result of the kinetic adsorption showed better pseudo-second orders. Overall, the conclusion of this study proved that banana bunch can be effectively used as an adsorbent for the removal of phenol and 2-chlorophenol.

\section{ACKNOWLEDGMENT}

This work was supported by the Chemistry Department of Faculty Mathematics and Natural Sciences and Direktorat Penelitian dan Pengabdian Masyarakat (DPPM) of Indonesia Islamic University(108/WD/70/Div.AU/III/2017).

\section{REFERENCES}

1. C. R. Girish, V. R. Murty, International Scholarly Research Notices, Article ID 201626 (2014), DOI: $10.1155 / 2014 / 201626$

2. A. Allwar, H. Z. Febriyanti, R.A. Yuliantari, Asian Journal of Applied Sciences, 11(1), 20(2018), DOI: 10.3923/ajaps.2018.20.28 


\section{RASĀYAN J. Chem.}

Vol. 12 | No. 2 |598-607 | April - June | 2019

3. Y. Zhang, J. Zheng, X. Qu, H. Chen, Journal of Colloid and Interface Science, 316(2), 523(2007), DOI:10.1016/j.jcis.2007.08.013

4. B. Jiang, J. Zheng, X. Lu, Q. Liu, M. Wu, Z. Yan, S. Qiu, Q. Xue, Z. Wei, H. Xiao, M. Liu, Chemical Engineering Journal, 215-216, 969(2013), DOI:10.1016/j.cej.2012.11.046

5. W. Shen, Z. Li, Y. Liu, Recent Patent on Chemical Engineering, 1(1), 27 (2008), DOI: $10.2174 / 2211334710801010027$

6. D. Chen, Z. Zeng, Y. Zeng, F. Zhang, M. Wang, Water Resources and Industry, 15, 100 (2016), DOI:10.1016/j.wri.2016.05.003

7. A. Allwar, Rasayan J. Chemistry, 11(1), 280(2018), DOI:10.7324/RJC.2018.1112000

8. G.D. Samuel, J.E.R.Dhas, G. Ramanan, M. Ramachandran, Rasayan J. Chemistry, 10(3), 784(2017), DOI:10.7324/RJC.2017.1031748

9. S. Mopoung, P. Moosri, W. Palas, S. Khumpai, Hindawi Publishing Corporation the Scientific World Journal, Article ID 415961(2015), DOI:10.1155/2015/415961

10. Y. Ma, N. Gao, W. Chu, C. Li, C, Front. Environ. Sci. Eng., 7(2), 158(2013), DOI:10.1007/s11783012-0479-7

11. M. A. Atieh, APCBEE Procedia, 10, 136(2014), DOI: 10.1016/j.apcbee.2014.10.031

12. M.A. Ajeel, M.K. Aroua, W.M.A. Wan Daud, Electrochimica Acta, 180, 20(2015), DOI:10.1016/j.electacta.2015.08.062

13. M. Afsharnia, M. Saedi, A. Zarei, M. R Narooie, H. Biglari, Electronic Physician, 8(11), (2016), DOI: $10.19082 / 3248$

14. H. Cherifi, S. Hanini, F. Bentahar, Desalination. 244(1-3), $177 \quad$ (2009), DOI:10.1016/j.desal.2008.05.022

15. R. Sarvani, E. Damani, S. Ahmadi, Iranian Journal of Health Sciences, 6(1), 33 (2018), DOI: $10.29252 /$ jhs.6.1.33

16. H. Allaboun, F. A. Al-Rug, Materials, 9(4), 251(2016), DOI:10.3390/ma9040251

17. S. Bousba, A. H. Menial, Chemical Engineering Transactions, 35(2013), DOI:10.3303/CET1335143

18. Y. MA, N. GAO, W. CHU, C. Li, Front. Environ. Sci. Eng., 7(2), 158(2013), DOI:10.1007/s11783012-0479-7

19. E. M. Solima, H. M. Albishri, H. M. Marwani, M. G. Batterjee, Desalination and Water Treatment, 51(34-36), (2013), DOI:10.1080/19443994.2013.792144

[RJC-5090/2018] 